\title{
Improvement of Sliding Mode Power Control for WECS based on DFIG-Generator
}

\author{
BTISSAM MAJOUT \& DOUAE ABRAHMI, YASMINE IHEDRANE, CHAKIB EL BAKKALI, \\ KARIM MOHAMMED, BADRE BOSSOUFI
}

\section{LIMAS Laboratory, Faculty of Sciences Dhar El Mahraz, Sidi Mohamed Ben Abdellah University, Fez, MOROCCO}

Abstract: In this work, we are developing a new strategy for controlling wind systems based on the DFIG Generator. The SMC sliding mode technique is based on the principle of Lyapunov stability in order to make a nonlinear system close to linearity. The use of such a technique with an improvement in regulators to eliminate the Chattering phenomenon shows a great improvement in the performance of wind systems. which is based on performance estimators to improve the quality of the system. The energy quality at the output of the wind system will be injected into the distribution network according to international standards. The proposed model is validated on the Matlab \& Simulink environment to test trajectory tracking and robustness.

Key-Words: Wind power generator system; SMC Control; PMSG; MPPT; MATLAB/SIMULINK)

Received: September 12, 2019. Revised: February 25, 2020. Accepted: March 9, 2020. Published: March 16, 2020.

\section{Introduction}

In the recent decades, the scarcity of fossil fuels and their impact on the environment have led to increase the usage of alternative energy resources, such as wind and solar energy. Hence, the growing interest about the electrical energy produced from the wind power from the industries.

Today, most installed wind turbines are equipped with asynchronous double-feed machines (DFIG). Indeed, this type of machine has several advantages such as their ability to produce electrical energy at variable speed and extract the maximum possible power, Where The interest of variable speed for a wind turbine is to be able to operate on a large range of wind speeds, and to be able to derive the maximum power possible for each wind speed. Thus their accessibility to the stator and the rotor which offers the opportunity to have several degrees of freedom to properly control the transfer of power and the power factor. Where we can have the rotor circuit controlled by a low power converter relatively to the stator. DFIG is subject to many constraints, such as the effects of parametric uncertainties (due to overheating, saturation, etc.) and the disturbance of the speed variation, which could divert the system from its optimal functioning. purpose of solving this kind of problems we have referred to the use of the command by sliding mode.

\section{Modeling of Wind System Based on DFIG}

The conversion chain includes in series a speed multiplier to increase the speed of rotation to about $1500 \mathrm{rpm}$, a doubly fed induction generator(DFIG) operating at variable speed, Three-phase converters adjust the frequency of the wind turbine to that of the electricity grid to which it is connected $(50 \mathrm{~Hz}$ in Morocco).

The transformation of the power of the aerogenerator into kinetic energy then into mechanical energy of rotation is done in two parts: at the turbine rotor (primary shaft), which captures part of the kinetic energy of the wind present to

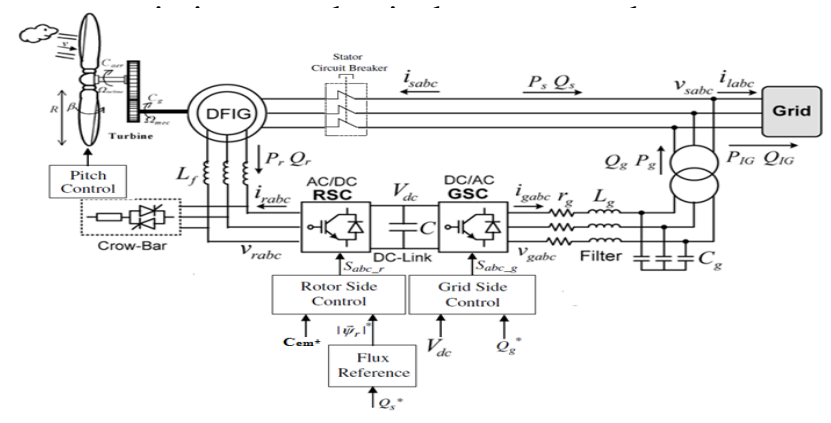

Figure 1. Architecture of the Control

\subsection{Wind-Turbine model}

The model of the turbine is modeled from the following system of equations: [7-8]:

$$
P_{\text {incident }}=\frac{1}{2} \cdot \rho \cdot S \cdot v^{3}
$$




$$
\begin{aligned}
& P_{\text {extracted }}=\frac{1}{2} \cdot \rho \cdot S \cdot C_{p}(\lambda, \beta) \cdot v^{3} \\
& \lambda=\frac{\Omega_{t} \cdot R}{v} \\
& C_{p}^{\max }(\lambda, \beta)=\frac{16}{27} \approx 0.593 \\
& C_{p}(\lambda, \beta)=c_{1} \cdot\left(c_{2} \cdot \frac{1}{A}-c_{3} \cdot \beta-c_{4}\right) \cdot e^{-c_{5} \frac{1}{A}}+c_{6} \cdot \lambda \\
& \frac{1}{A}=\frac{1}{\lambda+0.08 \cdot \beta}-\frac{0.035}{1+\beta^{3}} \\
& C_{a l}=\frac{P_{e o l}}{\Omega_{t}}=\frac{1}{2} \cdot \rho \cdot S \cdot C_{p}(\lambda, \beta) \cdot v^{3} \cdot \frac{1}{\Omega_{t}} \\
& J=\frac{J_{\text {tur }}}{G^{2}}+J J_{g} \\
& J \frac{d \Omega_{\text {mec }}}{d t}=C_{\text {mec }}=C_{a r}-C_{e m}-f \cdot \Omega_{\text {mec }}
\end{aligned}
$$

$S:$ the area swept by the pales of the turbine $\left[\mathrm{m}^{2}\right]$ $\rho$ : the density of the air $\left(\rho=1.225 \mathrm{~kg} / \mathrm{m}^{3}\right.$ at atmospheric pressure). $v$ : wind speed $[\mathrm{m} / \mathrm{s}] . C p(\lambda$, $\beta$ ): the power coefficient. $\lambda$ : the specific speed. $\beta$ : the angle of orientation of the blades. $P_{\text {extracted: the }}$ power extracted of the turbine.

$\Omega_{t}$ : Rotational speed of the turbine. $C_{a l}$ : Torque on the slow axis (turbine side). $J_{t u r}$ : turbine inertia. $J_{g}$ : inertia of the generator. $\Omega_{m e c}$ : Mechanical speed of DFIG. $C_{a r}$ : Aerodynamic torque on the fast axis of the turbine

The Fig.2 shows the evolution of the power coefficient as a function of $\lambda$ for different values of $\beta$. A coefficient of maximum power of $\mathrm{Cp}=0.564$ is obtained for a speed ratio $\lambda$ which is (3) ( $\lambda o p t)$. Fixing $\beta$ and $\lambda$ respectively to their optimal values, the wind system provides optimal power.

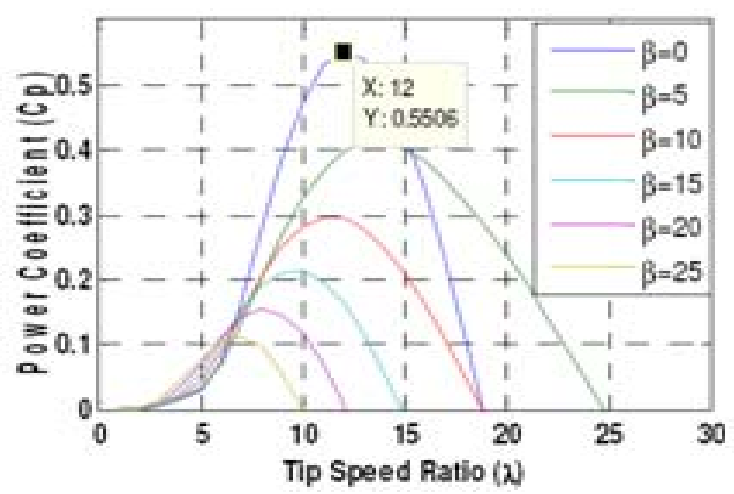

Figure 2. Curves of the power coefficient

\subsection{Maximization of power control without speed control.}

while the variation of the wind speed in steady state is low compared to the electrical time constants of the system, we assume that the speed of rotation of the DFIG is fixed and neglecting the effect of the viscous torque $f$, the dynamic equation of the turbine becomes (12); from (12) we obtain the static equation describing the stationary state of the turbine (13); The reference electromagnetic torque is determined from an estimate of the aerodynamic torque given by (14),we obtain equation (15); The orientation angle of the blades $\beta$ is assumed to be constant and the estimated speed of the turbine is calculated from the mechanical speed (16); The estimated wind speed is given by equation (17); on the Base of the previous equations, we can then write the equation of the reference electromagnetic couple (18).

$$
\begin{aligned}
& \left\{\begin{array}{l}
J_{\text {tot }} \cdot \frac{d \Omega_{m e c}}{d t}=C_{g}-C_{e m}-f \cdot \Omega_{m e c}=0 \\
C_{g}=C_{e m}=\frac{C_{a e r o}}{G} \\
C_{\text {aero } o_{e s t}}=\frac{1}{2 \cdot \Omega_{t_{e s t}}} \cdot C_{p_{\text {max }}}\left(\lambda_{\text {opt }}, \beta\right) \cdot \rho \cdot \pi \cdot R^{2} \cdot v_{\text {est }}^{3} \\
C_{\text {em }}=\frac{C_{\text {aero }}}{G}
\end{array}\right. \\
& \Omega_{t_{e s t}}=\frac{\Omega_{m e c}}{G} \\
& v_{\text {est }}=R \cdot \frac{\Omega_{\text {est }}}{\lambda_{\text {opt }}} \\
& C_{\text {em_ref }}=\frac{\rho \cdot \pi \cdot R^{5} \cdot C_{p_{\_} \max }\left(\lambda_{\text {opt }}\right) \cdot \Omega_{m e c}^{2}}{2 \cdot \lambda_{\text {opt }}^{3} \cdot G^{3}}
\end{aligned}
$$

\subsection{DFIG Model}

The equations of the stator voltages $\mathrm{Vs}(\mathrm{d}, \mathrm{q})$ and the rotor $\operatorname{Vr}(\mathrm{d}, \mathrm{q})$ of the DFIM in the reference of Park are written as follows: $[9,13]$ :

Voltages at the stator:

$\left\{\begin{array}{l}V_{s d}=R_{s} \cdot i_{s d}+\frac{d \psi_{s d}}{d t}-\omega_{s} \cdot \psi_{s q} \\ V_{s q}=R_{s} \cdot i_{s q}+\frac{d \psi_{s q}}{d t}+\omega_{s} \cdot \psi_{s d}\end{array}\right.$

- Voltages at the stator:

$\left\{\begin{array}{l}V_{r d}=R_{r} \cdot i_{r d}+\frac{d \psi_{r d}}{d t}-\omega_{r} \cdot \psi_{r q} \\ V_{r q}=R_{r} \cdot i_{r q}+\frac{d \psi_{r q}}{d t}+\omega_{r} \cdot \psi_{r d}\end{array}\right.$

With: $\omega_{s}-\omega_{r}=p . \omega$

The magnetic equations are expressed by the flux expressions in the reference (d, q).

- Flux at the stator : 
$\left\{\psi_{s d}=L_{s} \cdot \psi_{s d}+M \cdot i_{r d}\right.$

$\left\{\psi_{s q}=L_{s} \cdot \psi_{s q}+M \cdot i_{r q}\right.$

- Flux at the rotor :

$\left\{\psi_{r d}=L_{r} \cdot \psi_{r d}+M \cdot i_{s d}\right.$

$\left\{\psi_{r q}=L_{r} \cdot \psi_{r q}+M \cdot i_{s q}\right.$

With: $M=M_{s r}=M_{r s}$

The electromagnetic torque is expressed as a function of the currents and the flows by:

$$
\left\{\begin{array}{l}
C_{e m}=p \cdot\left(\psi_{s d} \cdot i_{s q}+\psi_{s q} \cdot i_{s d}\right) \\
C_{e m}=p \cdot\left(\psi_{r q} \cdot i_{r d}-\psi_{r d} \cdot i_{r q}\right)
\end{array}\right.
$$

The fundamental equation of dynamics is:

$$
C_{e m}=C_{r}+J \cdot \frac{d \Omega}{d t}+f . \Omega
$$

With:

$V_{s(d, q),} V_{r(d, q)}$ : Stator and rotor voltages in the reference of Park.

$I_{s(d, q),} I_{r(d, q)} \quad:$ Stator and rotor currents in the reference of Park.

$\psi_{s(d, q)}, \psi_{r(d, q)}$ : Stator and rotor flux in the reference of Park.

$R_{s}, R_{r}, L_{s}, L_{r} \quad:$ Stator and rotor resistances and inductances.

$M \quad$ : Mutual inductance.

$C_{r} C_{e m}$ : Load torque and Electromagnetic torque.

$\Omega \quad$ : Rotation speed of the machine $(\omega=\mathrm{p} . \Omega)$.

$J, f$ : Moment of inertia and Coefficient of viscous friction.

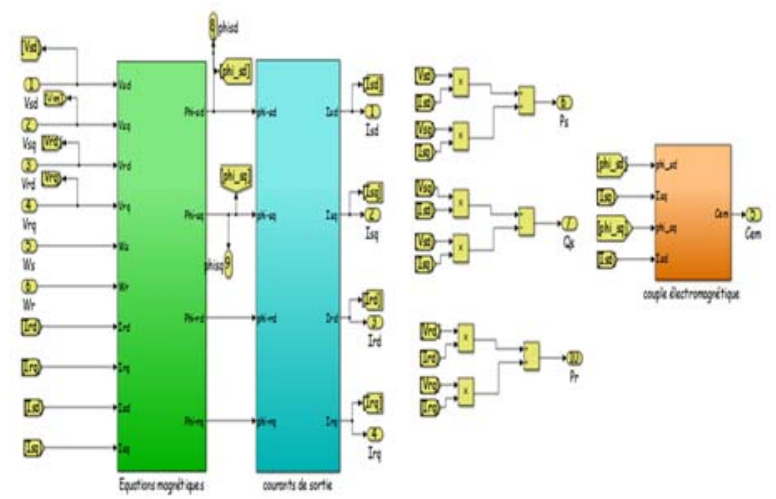

Figure 4. Simulink Model of the DFIG

1.4. Model of the two-level voltage inverter:

The two-level voltage inverter controls the powers (active and reactive) exchanged between the generator and the network. In order to facilitate the modeling of the power converter, Each inverter arm consists of two semiconductor switches assumed to be perfect and functioning in a complementary manner. It can be used in inverter mode or in rectifier mode (the modeling remains valid for both cases).The output voltage of the two three-phase converters GSC (inverter) and RSC (rectifier) is controlled by sinusoidale pulse width modulation technique (PWM) which allows simultaneous adjustment of the frequency and the RMS value of the output voltage.

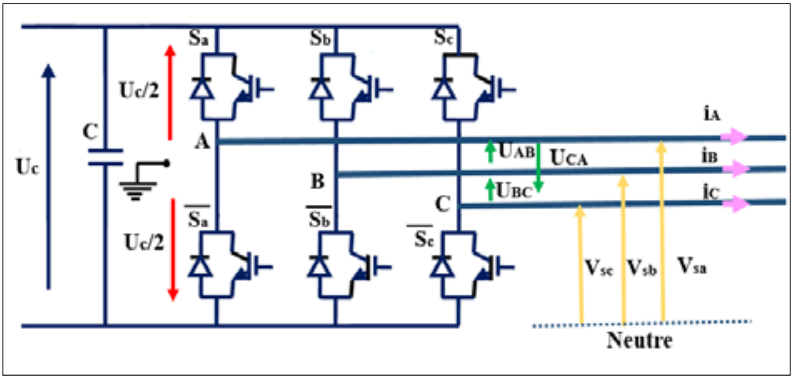

Figure 5. Diagram of the two-level inverter

The $\mathrm{Sa}, \mathrm{Sb}, \mathrm{Sc}$ is the state of the upper switches of each arm of the inverter.

- The expression of the simple voltages is presented by the following system:

$\left\{\begin{array}{l}v_{A}=\frac{1}{3}\left(U_{A B}-U_{C A}\right)=\frac{1}{3}\left(2 \cdot v_{A}-v_{B}-v_{C}\right) \\ v_{B}=\frac{1}{3}\left(U_{B C}-U_{A B}\right)=\frac{1}{3}\left(2 \cdot v_{B}-v_{A}-v_{C}\right) \\ v_{C}=\frac{1}{3}\left(U_{C A}-U_{B C}\right)=\frac{1}{3}\left(2 \cdot v_{C}-v_{A}-v_{B}\right)\end{array}\right.$

- The matrix form of simple tensions becomes:

$\left[\begin{array}{l}v_{A} \\ v_{B} \\ v_{C}\end{array}\right]=\frac{1}{3}\left[\begin{array}{ccc}2 & -1 & -1 \\ -1 & 2 & -1 \\ -1 & -1 & 2\end{array}\right] \cdot\left[\begin{array}{l}v_{A O} \\ v_{B O} \\ v_{C O}\end{array}\right]$

We associated with Each arm of the inverter a binary command value $\mathrm{Si}$, where $\mathrm{i}=\mathrm{a}, \mathrm{b}, \mathrm{c}$ :

$\left[\begin{array}{l}v_{A O} \\ v_{B O} \\ v_{C O}\end{array}\right]=\frac{U_{C C}}{2}\left[\begin{array}{l}S_{a} \\ S_{b} \\ S_{C}\end{array}\right]$

We replace (25) in (24), we get:

$\left[\begin{array}{l}v_{A} \\ v_{B} \\ v_{C}\end{array}\right]=\frac{U_{C C}}{6} \cdot\left[\begin{array}{ccc}2 & -1 & -1 \\ -1 & 2 & -1 \\ -1 & -1 & 2\end{array}\right] \cdot\left[\begin{array}{l}S_{a} \\ S_{b} \\ S_{C}\end{array}\right]$

The single voltages of the inverter become proportional to the states of the control quantities of the switches ( $\mathrm{Sa}, \mathrm{Sb}, \mathrm{Sc}$ ).

\subsection{DC-Bus model}

The DC bus interconnects the two converters of the wind system (RSC and GSC). The latter allows the transfer of power between two sources at different frequencies. It is modeled by equations (27);

$\left\{\begin{array}{l}W_{d c}=\int P_{c} \cdot d t=\frac{1}{2} \cdot C \cdot V_{d c}^{2} \\ \frac{d V_{d c}^{2}}{d t}=\frac{2}{C}\left(P_{f}-P_{r}\right)\end{array}\right.$ 


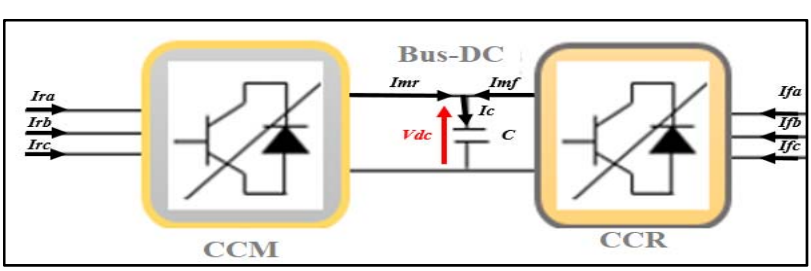

Figure 6. Diagram of the continuous bus

1.6. RL Filter Model

The intermediate filter used is of the RL type. The currents passed between the GSC converter and the network are imposed by the coils constituting the low pass filter. The expressions of the voltages at the terminals of the filters in the the park referential are presented by (28).

$\left\{\begin{array}{c}v_{d f}=-R_{f} \cdot I_{d f}-L_{f} \cdot \frac{d I_{d f}}{d t}+\omega_{s} \cdot L_{f} \cdot I_{q f} \\ v_{q f}=-R_{f} \cdot I_{q f}-L_{f} \cdot \frac{d I_{q f}}{d t}-\omega_{s} \cdot L_{f} \cdot I_{d f}+v_{s}\end{array}\right.$

\section{Sliding mode controller}

The basic idea of sliding mode control design is first to attract the states of the system to a suitably selected region, and then to design a control law that will always keep the system in that region. Where the design of the sliding mode control algorithm is defined by three complementary steps:

\subsection{Choice of sliding surface}

For a non-linear system presented in the following form (29), where $A(x, t)$ and $B(x, t)$ are two continuous and uncertain non linear functions assumed to be bounded.

$$
\left\{\begin{array}{l}
x \dot{(t})=A(x, t)+B(x, t) u(t) ; x \in R^{n}, u \in R \\
(x)=\left(\frac{d}{d t}+\delta\right)^{n-1} * e(x) \\
e(x)=x^{d}-x \\
\quad x=\left[x, \dot{x}, \ldots x^{n-1}\right]^{T} ; x^{d}=\left[x^{d}, \dot{x}^{d}, \ldots \ldots\right]^{T}
\end{array}\right.
$$

\subsection{Convergence and existence conditions}

To make the surface attractive and invariant, we returned to the second theorem of LYAPUNOV where the scalar function is defined positive by (32). The derivative of this function gives (33), and to guarantee the existence of the sliding mode, where the sliding variable $S(x, t)$ tends towards zero, it suffices to ensure that (33) is defined negative (34).

$$
\left\{\begin{array}{c}
V(x)=\frac{1}{2} \cdot S(x)^{2} \\
V \dot{(x)}=S(x) S(x) \\
S(x) S(x)<0
\end{array}\right.
$$

\subsection{Determination of the Law of Control}

The control law is defined by the relation (35), With: $\mathrm{u}^{+}$and $\mathrm{u}^{-}$are continuous functions (36) where $\mathrm{u}^{-} \neq \mathrm{u}^{+}$. The control by sliding modes is composed of two terms: $\mathrm{u}_{\mathrm{eq}}$ : the equivalent control vector, $\mathrm{u}_{\mathrm{n}}$ : The stabilizing command.

$u=u_{e q}+u_{n}$
$u=\left\{\begin{array}{l}u^{+}(x) \text { si } s(x, t)>0 \\ u^{-}(x) \text { si } s(x, t)<0\end{array}\right.$

$\checkmark$ Determination of the equivalent command ueq:

$S(x)=\frac{d S}{d t}=\frac{\partial S}{\partial x} \cdot \frac{\partial x}{\partial t}$

$\dot{S(x)}=\frac{d S}{d t}=\frac{\partial S}{\partial x}\left(A(x, t)+B(x, t)\left(u_{e q}+u_{n}\right)\right)$

$\dot{S(x)}=\frac{d S}{d t}=\frac{\partial S}{\partial x}\left(A(x, t)+B(x, t) u_{e q}\right)+$

$\frac{\partial S}{\partial x} B(x, t) u_{n}$

$u_{e q}(t)=\left(-\frac{\partial S}{\partial x} A(x, t)\right)\left(\frac{\partial S}{\partial x} B(x, t)\right)^{-1}$

\section{$\checkmark$ Determination of the basic discontinuous command un:}

The simplest discontinuous command $\mathrm{u}_{\mathrm{n}}$ is given by (45), where $\mathrm{K}$ is the command gain. This type of control has a drawback known by "CHATTERING". To solve this problem in this case we replaced the "SIGN" function by the "SAT" function:

$$
\begin{aligned}
& u_{n}=K \cdot \operatorname{sign}(S(x)) \\
& \operatorname{Sat}(S)=\left\{\begin{array}{l}
\operatorname{Sat}(S)=1 \text { si } S>\varepsilon \\
\operatorname{Sat}(S)=-1 \text { si } S<\varepsilon \\
\operatorname{Sat}(S)=\frac{S}{\varepsilon} \text { si }|S|<\varepsilon
\end{array}\right.
\end{aligned}
$$

\section{Application Of The Sliding Mode Command To The DFIG}

4.1. Control of the converter on the DFIG (RSC) side and on the Grid side (GSC)

Considering the sliding surface proposed by SLOTINE (30), For $n=1$; the sliding surface of the active and reactive power is given by (47), where Psref and Qsref are the references of stator powers (active and reactive) of DFIG and Qfref and Pfref are the references of powers (reactive and active) of RL filter.

$$
\left\{\begin{array}{c}
S\left(P_{s}\right)=e_{1}=P_{\text {sref }}-P_{s} \\
S\left(Q_{s}\right)=e_{2}=Q_{\text {sref }}-Q_{s} \\
S\left(P_{f}\right)=e_{3}=P_{\text {fref }}-P_{f} \\
S\left(Q_{f}\right)=e_{4}=Q_{\text {fref }}-Q_{f}
\end{array}\right.
$$




$$
\left\{\begin{array}{c}
S\left(\dot{P}_{s}\right)=\dot{e}_{1}=\dot{P}_{\text {sref }}-\dot{P}_{s} \\
S\left(\dot{Q}_{s}\right)=\dot{e}_{2}=\dot{Q}_{\text {sref }}-\dot{Q}_{s} \\
S\left(\dot{P}_{f}\right)=\dot{e}_{3}=\dot{P}_{\text {fref }}-\dot{P}_{f} \\
S\left(\dot{Q}_{f}\right)=\dot{e}_{4}=\dot{Q}_{\text {fref }}-\dot{Q}_{f}
\end{array}\right.
$$

With:

$$
\left\{\begin{array}{c}
\dot{P}_{s}=-\frac{v_{s} \cdot M}{L_{s}} \dot{I}_{r q} \\
\dot{Q}_{s}=\frac{v_{s}^{2}}{\omega_{s} \cdot L_{s}}-\frac{v_{s} \cdot M}{L_{s}} \dot{I}_{r d} \\
\dot{I}_{r d}=\frac{V_{r d}}{L_{r} \cdot \sigma}-\frac{R_{r}}{L_{r} \cdot \sigma} \cdot I_{r d}+\omega_{r} \cdot I_{r q} \\
\dot{I}_{r q}=\frac{V_{r q}}{L_{r} \cdot \sigma}-\frac{R_{r}}{L_{r} \cdot \sigma} \cdot I_{r q}-\omega_{r} \cdot I_{r d}-\omega_{r} \cdot \frac{M \cdot V_{s}}{L_{r} \cdot L_{s} \cdot \sigma \cdot \omega_{s}}
\end{array}\right.
$$

We replace each term by its expression given by (49), the derivative of the sliding surface becomes as follows (50) (51):

$\left\{\begin{array}{c}\dot{e}_{3}=\dot{P}_{s r e f}+\frac{V_{s} \cdot R_{f}}{L_{f}} I_{q f}+\frac{V_{s}\left(V_{f q e q}+V_{f q n}\right)}{L_{f}}+\omega_{s} \cdot V_{s} \cdot I_{d f}-\frac{V_{s}^{2}}{L_{f}} \\ \dot{e}_{4}=\dot{Q}_{s r e f}-\frac{V_{s} \cdot R_{f}}{L_{f}} I_{d f}-\frac{V_{s}\left(V_{f d e q}+V_{f d n}\right)}{L_{f}}+\omega_{s} \cdot V_{s} \cdot I_{q f}\end{array}\right.$

According to the sliding mode and the permanent mode, we have (54) (56); By replacing the equation ((54) in (52)) and ((56) in (53)), the expression of the equivalent Veq command becomes (57) (58); the stabilizing command is given by equation (59) (60); finally the expression of the total order (Vrd, Vrq) and (Vfd, Vfq) becomes (61) (62).

$$
\begin{aligned}
& \left\{\begin{array}{c}
e_{1,2}=0 \\
\dot{e}_{1,2}=0 \\
V_{r d n}=V_{r q n}=0
\end{array}\right. \\
& \left\{\begin{array}{c}
e_{3,4}=0 \\
\dot{e}_{3,4}=0 \\
V_{f d n}=V_{f q n}=0
\end{array}\right. \\
& \left\{\begin{array}{c}
V_{r d e q}=-\frac{L_{r} \cdot L_{s} \cdot \sigma}{M \cdot V_{s}} \dot{Q}_{s r e f}+R_{r} \cdot I_{r d}-\omega_{r} \cdot L_{r} \cdot \sigma \cdot I_{r q} \\
V_{r q e q}=-\frac{L_{r} \cdot L_{s} \cdot \sigma}{M \cdot S_{s}} \dot{P}_{\text {sref }}+R_{r} \cdot I_{r q}+\omega_{r} \cdot L_{r} \cdot \sigma \cdot I_{r d}+\omega_{r} V_{s} \frac{M}{L_{s} \cdot \omega_{s}}
\end{array}\right. \\
& \left\{\begin{array}{c}
V_{f d e q}=\frac{L_{f}}{V_{s}} \dot{Q}_{\text {sref }}-R_{f} \cdot I_{d f}+L_{f} \cdot \omega_{s} \cdot I_{q f} \\
V_{f q e q}=\frac{L_{f}}{V_{s}} \dot{P}_{\text {sref }}-R_{f} \cdot I_{q f}-L_{f} \cdot \omega_{s} \cdot I_{d f}+V_{s}
\end{array}\right. \\
& \left\{\begin{array}{l}
V_{r d n}=K_{r d n} \cdot S a t\left(e_{1}\right) \\
V_{r q n}=K_{r q n} \cdot \operatorname{Sat}\left(e_{2}\right)
\end{array}\right. \\
& \left\{\begin{array}{l}
V_{f d n}=K_{f d n} \cdot S a t\left(e_{4}\right) \\
V_{f q n}=K_{f q n} \cdot S a t\left(e_{3}\right)
\end{array}\right. \\
& \left\{\begin{array}{l}
V_{r d}=-\frac{L_{r} \cdot L_{s} \cdot \sigma}{M \cdot V_{s}} \cdot \dot{Q}_{s r e f}+R_{r} \cdot I_{r d}-\omega_{r} \cdot L_{r} \cdot \sigma \cdot I_{r q}+K_{d} s a t\left(e_{2}\right) \\
V_{r q}=-\frac{L_{r} \cdot L_{s} \cdot \sigma}{M \cdot V_{s}} \cdot \dot{P}_{\text {sref }}+R_{r} \cdot I_{r q}+\omega_{r} \cdot L_{r} \cdot \sigma \cdot I_{r d}+\omega_{r} \cdot M \cdot \frac{V_{s}}{L_{s} \cdot \omega_{s}}
\end{array}\right.
\end{aligned}
$$

\footnotetext{
$\left\{\begin{array}{c}V_{f d}=-\frac{L_{f}}{V_{s}} \cdot \dot{Q}_{f r e f}-R_{f} \cdot I_{d f}+\omega_{s} \cdot L_{f} \cdot I_{q f}+K_{d f n} \operatorname{sat}\left(e_{4}\right) \\ V_{f q}=-\frac{L_{f}}{V_{s}} \cdot \dot{P}_{f r e f}-R_{f} \cdot I_{q f}-\omega_{s} \cdot L_{f} \cdot I_{d f}+V_{s}+K_{q f n} \operatorname{sat}\left(e_{3}\right)\end{array}\right.$
}

\section{Simulation \& Resuls}

To verify the performance and stability of the control system by SMC control, the DFIG is subject to two robustness tests (the Tracking and Regulation Tests for SMC and the robustness tests regarding the variation parameters)

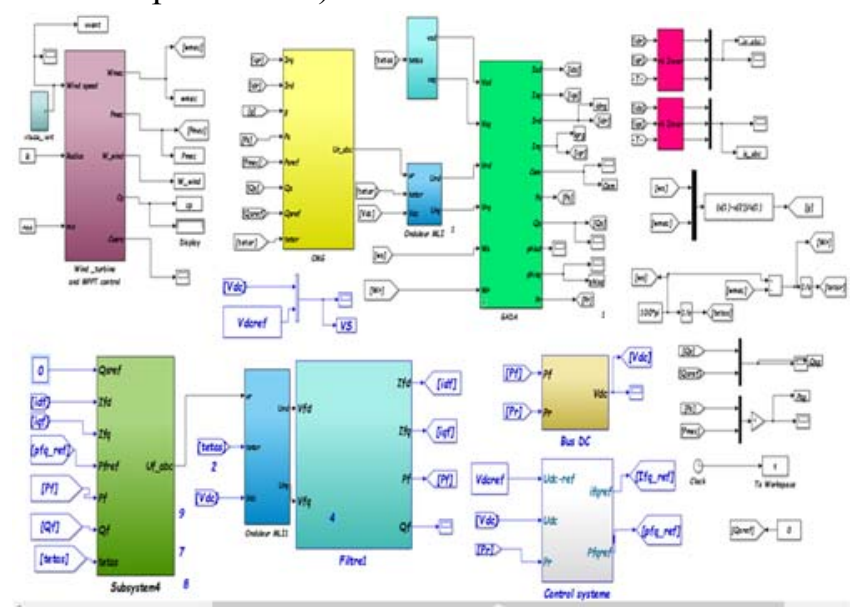

Figure 6. Simulation scheme of the sliding mode control on MATLAB and Simulink environment

\subsection{Tracking and Regulation for SMC}

In this test, we considered the aerodynamic power according to the MPPT as a reference of active power, and zero as reference for reactive power.

$\checkmark$ Test with constant speed (rung speed):
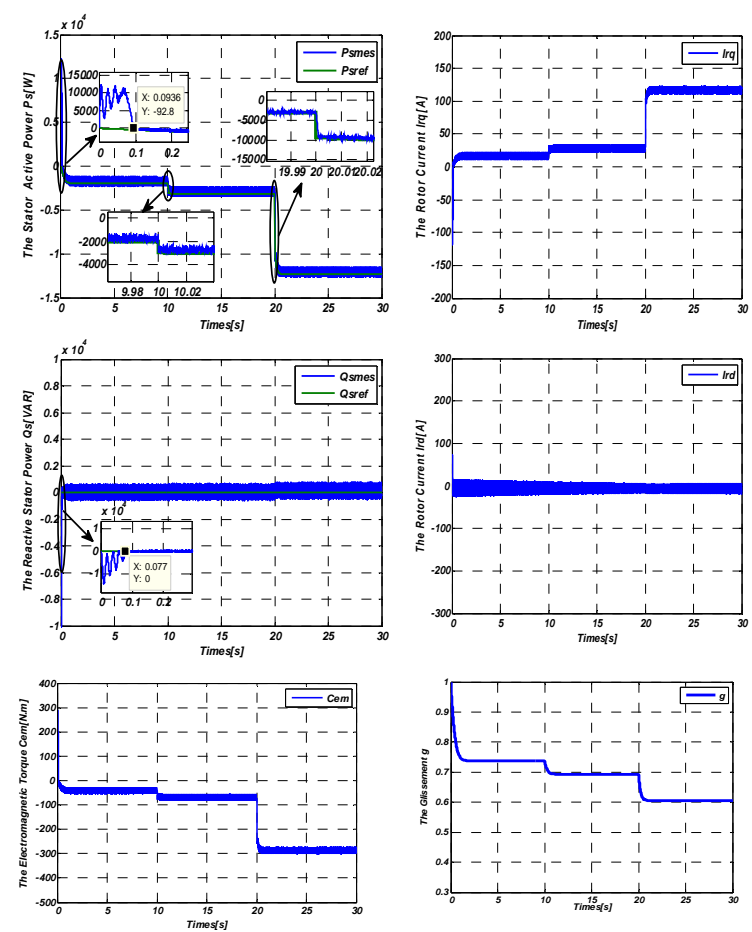

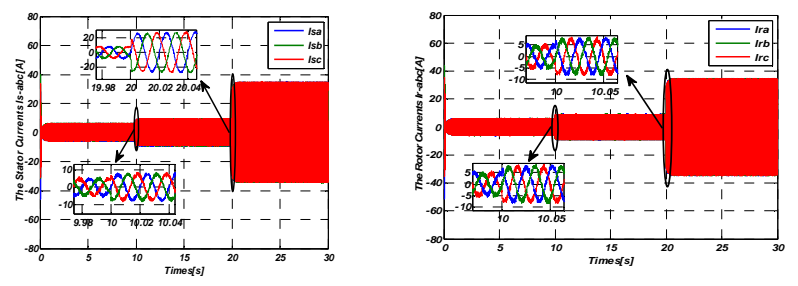

Figure 7. Results of the control by sliding mode of the DFIG

According to the curves illustrated in figure (8) we note that the power references are perfectly followed by the DFIG generator, where the continous bus DC perfectly follows its reference value without overshoot and with a low response time, and the rotor currents Ir-abc and the threephase stator currents Is-abc generated by the GFID, are of the sinusoidal form with a fixed frequency $50 \mathrm{~Hz}$ for the stator currents. This implies clean energy without harmonics exchanged between DFIG and the electricity network.

$\checkmark$ Test with variable speed:

During this test the wind profile illustrated in figure (8) was applied to the DFIG.
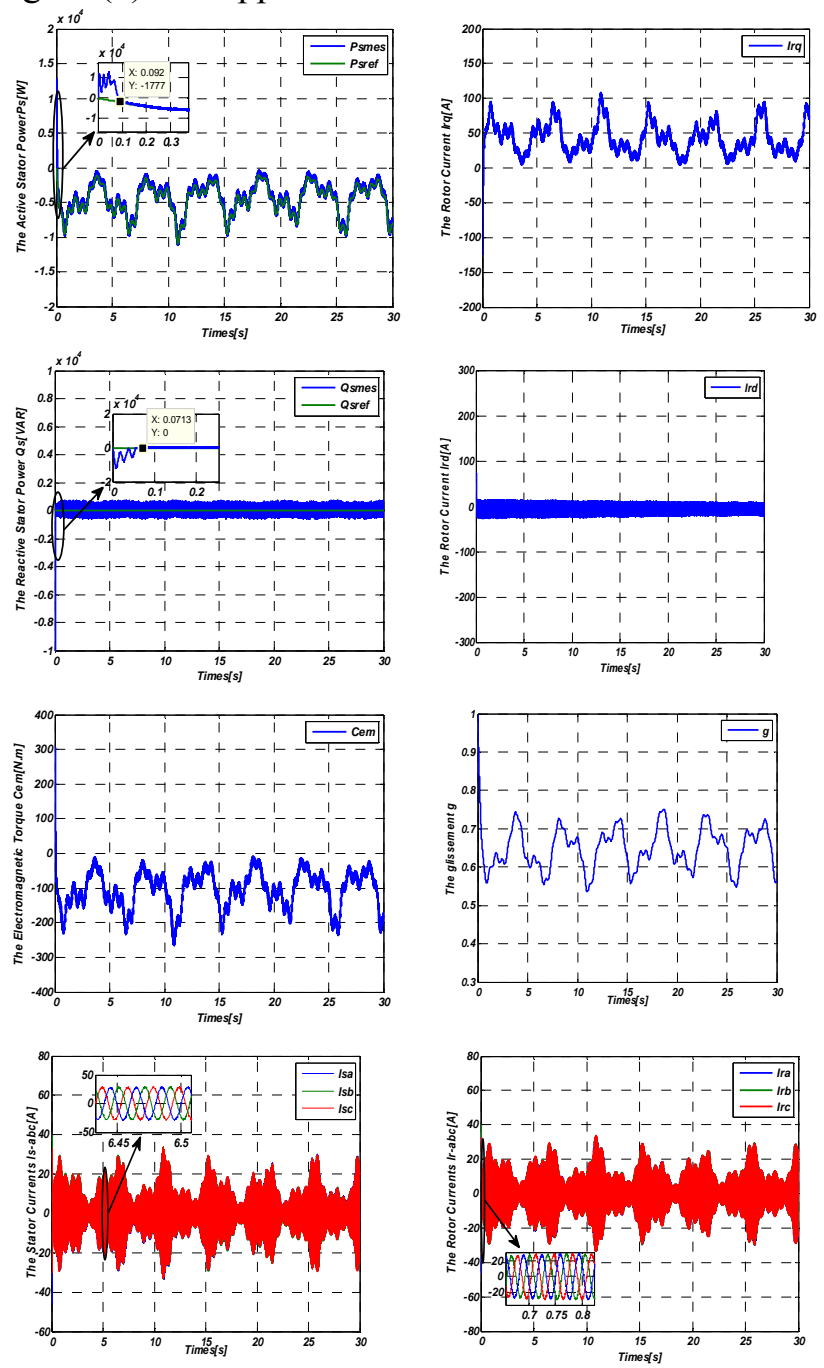

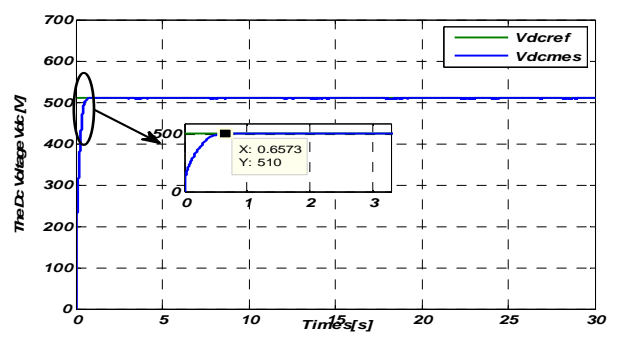

Figure 8 . Results of the control by sliding mode at variable

According to the curves illustrated in the figure (10) we notice a good behavior of the machine in spite of the variation of the wind, where the generator follows the references of the powers without overshoot and with an almost zero error. And the electromagnetic torque of the DFIG varies according to the wind speed, and proportional to the active stator power generated. We can notice that in spite of the variations of the wind, the stator current Is-abc remains sinusoidal with a fixed frequency $50 \mathrm{~Hz}$ equivalent to that of the network. The DC bus voltage shows that it follows its reference value quickly without overshooting with a small static error. the slip value $g$ is negative this implies that the functioning of the DFIG is in hypo-synchronous

\section{$\checkmark$ Robustness Tests}

In this test, we varied the parametric variables of the DFIG (resistance Rr and Rs) by $+50 \%$ of their nominal values.
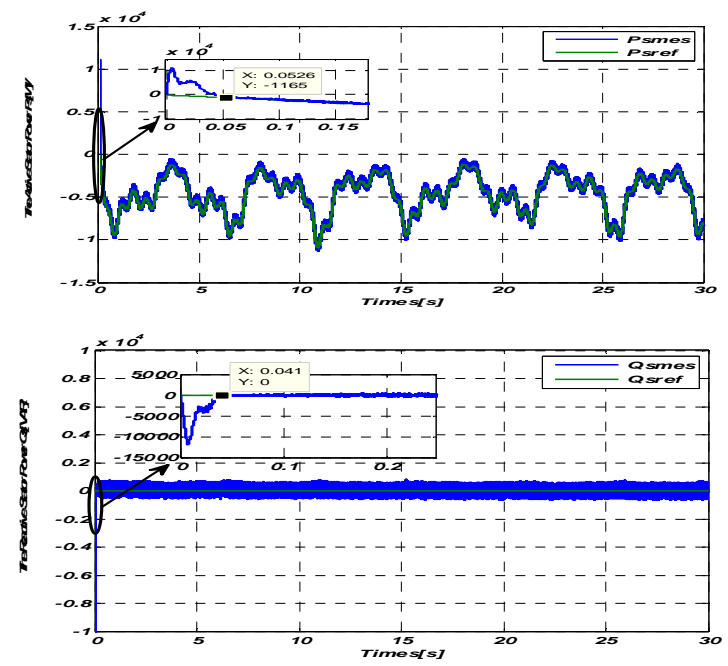

Figure 9. Robustness test with variation of resistances $\mathrm{Rr}$ and $\mathrm{Rs}$ for a variable wind speed It is noted that the decoupling between these two powers remains achievable with the same response time despite the variation of the resistance's $\mathrm{Rr}$ and Rs. This shows the robustness of the control by sliding mode facing this variation. 


\section{Conclusion}

The goal of this work is devoted to improving the power generated by a wind system by using different control algorithms to ensure a control structure achieving the best value simplicity, performance and stability. we started with MPPT control to ensure maximum power extraction. then, we implemented the sliding mode control which presents an optimal solution to the stability of nonlinear systems. Afterwards, we carried out the simulation in the Matlab / Simulink environment. and finally we applied a wind profile to the DFIG to analyze the behavior of the latter in dynamic regime. The results show that the sliding mode control system can be considered as an optimal solution in the field of renewable energies.

\section{REFERENCES}

[1] X. YU, K. STRUNZ, « Combined long-term and shortterm access storage for sustainable energy system », 2004 IEEE Power Engineering Society General Meeting, vol.2, pp.1946-1951, 10 June 2004.

[2] B.BOSSOUFI, H. ALAMI AROUSSI, EL.M.ZIANI, A.LAGRIOUI, A.DEROUICH "LowSpeed Sensorless Control of DFIG Generators Drive for Wind Turbines System" WSEAS TRANSACTIONS on SYSTEMS and CONTROL, pp514-525, Vol.9 No.4 November 2014.

[3] G. Poddar and V. T. Ranganathan, "Direct Torque and Frequency Control of Double- Inverter-Fed Slip-Ring Induction Motor Drive," IEEE Trans. Ind. Electron.,Vol. 51, No. 6, pp. 1329-1337, December 2004.

[4] G. Poddar and V. T. Ranganathan, "Sensorless Double-Inverter-Fed Wound-Rotor InductionMachine Drive," IEEE Trans. Ind. Electron., Vol. 53, No.1, pp. 86-95, February 2006.

[5] J. Dai, D. Xu, and B.Wu, "A Novel Control Scheme for Current-Source-Converter-Based PMSG Wind Energy Conversion Systems," IEEE Trans. Power Electron., Vol. 24, No. 4, pp. 963-972, April 2009.

[6] H. Akagi and H. Sato, "Control and Performance of a Doubly-Fed Induction Machine Intended for a Flywheel Energy Storage System," IEEE Trans. Power Electron., Vol. 17, No. 1, pp. 109-116, 2002.

[7] Liu, Y., Wang, Z., Xiong, L., Wang, J., Jiang, X., Bai, G., et al., 2018. DFIG wind turbine sliding mode control with exponential reaching law under variable wind speed. Int. J. Electr. Power Energy Syst. 96, 253-260.

[8] Lund, J.W., Boyd, T.L., 2016. Direct utilization of geothermal energy 2015 worldwide review. Geothermics 60, 66-93.

[9] Mahela, O.P., Shaik, A.G., 2016. Comprehensive overview of grid interfaced wind energy generation systems. Renew. Sustain. Energy Rev. 57, 260-281.
[10] Matraji, I., Al-Durra, A., Errouissi, R., 2018. Design and experimental validation of enhanced adaptive second-order SMC for PMSG-based wind energy conversion system. Int. J. Electr. Power Energy Syst. 103, 21-30.

[11] H. ALAMI AROUSSI, El.M. ZIANI, M. BOUDERBALA, B.BOSSOUFI, "Enhancement of the direct power control applied to DFIG-WECS", International Journal of Electrical and Computer Engineering, Vol. 10, No. 1, pp. 1511 1520, February 2020.

[12] H. Alami Aroussi, El.m. Ziani, M. Bouderbala, B.Bossoufi, "Improvement Of Direct Torque Control Applied To Doubly Fed Induction Motor Under Variable Speed", IJPEDS International Journal of Power Electronics and Drive System. Vol. 11, No. 1, pp. 1511 1520, March 2020.

[13] I. El Karaoui, M.Maaroufi, B.Bossoufi "Comparison of Power Control Methods in Wind Turbines using DFIG: Field Oriented Control and Sliding Mode Control" IJPEDS International Journal of Power Electronics and Drive System, Vol.11 No.4, December 2019.

[14] F. El Hammouchi, L. El Menzhi, A. Saad, Y. Ihedrane, B.BOSSOUFI "Wind turbine doubly-fed asynchronous machine diagnosis defects using stator and rotor currents lissajous curves" IJPEDS International Journal of Power Electronics and Drive System, Vol.10 No.2, pp 961-971, June 2019.

[15] Y. IHEDRANE, C. EL BEKKALI, M. EL GHAMRASNI, S.MENSOU, B.BOSSOUFI, "Improved Wind System using non-linear Power Control", Indonesian Journal of Electrical Engineering and Computer Science, Vol. 14, No. 3, pp. 1148 1158, June 2019.

[16] Y. IHEDRANE, C. El BEKKALI, B.BOSSOUFI, M. BOUDERBALA "Control of Power of a DFIG Generator with MPPT Technique for Wind Turbines Variable Speed", Renewable Energies book Modeling, Identification and Control Methods in Renewable Energy Systems, SPRINGER, pp 105129, 25 December 2018.

[17] M. BOUDERBALA, B.BOSSOUFI, A.LAGRIOUI, M.Taoussi, H. Alami Aroussi, Y. IHEDRANE, "Direct and indirect vector control of a doubly fed induction generator based in a wind energy conversion system", International Journal of Electrical and Computer Engineering, Vol. 9, No. 3, pp. 1531 1540, June 2018.

[18] Y. IHEDRANE, C. El BEKKALI, B.BOSSOUFI "Improved performance of DFIG-Generators for Wind Turbines Variable-Speed" IJPEDS International Journal of Power Electronics and Drive System, Vol.9 No.4, pp1875-1890, December 2018.

[19] M.TAOUSSI, M.KARIM, B.BOSSOUFI, D.HAMMOUMI, A.LAGRIOUI "Low-Speed Sensorless Control for Wind Turbine System" WSEAS TRANSACTIONS on SYSTEMS and CONTROL, pp405-417, Vol.12 No.1, December 2017. 
[20] Y. IHEDRANE, C. El BEKKALI, B.BOSSOUFI "Power Control of DFIG-Generators for Wind Turbines Variable-Speed" IJPEDS International Journal of Power Electronics and Drive System, Vol.8 No.1, pp 444-453, March 2017.

[21] B.BOSSOUFI, S.IONITA, H.ALAMI ARROUSSI, M.EL GHAMRASNI, Y.IHEDRANE "Managing voltage drops a variable speed wind turbine connected to the grid" IJAAC International Journal of Automation and Control, Vol.11, No. 1, January 2017.

[22] B.BOSSOUFI, M.KARIM, A.LAGRIOUI, M.TAOUSSI, A.DEROUICH "Observer Backstepping control of DFIG-Generators for Wind Turbines Variable-Speed: FPGA-Based Implementation" Renewable Energy Journal (ELSIVER), pp 903-917, Vol. 81. September 2015.

[23] H.MAHMOUDI, M. EL GHAMRASNI, A. LAGRIOUI, B. BOSSOUFI "Backstepping Adaptive Control Of DFIG-Generators For Wind Turbines Variable-Speed" Journal of Theoretical and Applied Information Technology JATIT, pp 320330, Vol. 81 No.2, 20th November 2015.

[24] H. ALAMI AROUSSI, El.M. ZIANI, B.BOSSOUFI, "ROBUST CONTROL OF A POWER WIND SYSTEM BASED ON THE DOUBLE FED INDUCTION GENERATOR (DFIG)" Journal of Theoretical and Applied Information Technology JATIT, pp 426-433, Vol. 83 No.3, 31th January 2016.

[25] B.BOSSOUFI, H. ALAMI AROUSSI, El.M.ZIANI, A.LAGRIOUI, A.DEROUICH "Low-Speed Sensorless Control of DFIG Generators Drive for Wind Turbines System" WSEAS TRANSACTIONS on SYSTEMS and CONTROL, pp514-525, Vol.9 No.4 November 2014.

[26] B.BOSSOUFI, M.KARIM, A.LAGRIOUI, M.TAOUSSI, A.DEROUICH "Adaptive Backstepping Control of DFIG Generators for WideRange Variable-speed Wind Turbines system" Journal of Journal of Electrical Systems JES, pp317330. Vol.10 No.3, September 2014.

[27] B.BOSSOUFI, M.KARIM, A.LAGRIOUI, M.TAOUSSI, M.L.EL Hafyani "Backstepping control of DFIG Generators for Wide-Range Variable-Speed Wind Turbines " IJAAC International Journal of Automation and Control , pp 122-140, Vol.8 No.2, July 2014.

[28] B.BOSSOUFI, M.KARIM, A.LAGRIOUI, M.TAOUSSI "FPGA-Based Implementation nonlinear backstepping control of a PMSM Drive" IJPEDS International Journal of Power Electronics and Drive System, pp 12-23 Vol.4 No.1, March 2014.

[29] B.BOSSOUFI, M.KARIM, A.LAGRIOUI, M.TAOUSSI, M. El GHAMRASNI "Backstepping Adaptive Control of DFIG-Generators for VariableSpeed Wind Turbines" IJCT International Journal of Computers \& Technology, pp3719-3733, Vol.12 No.7, February 2014.
[30] B.BOSSOUFI, M.KARIM, A.LAGRIOUI, "FPGABased Implementation Sliding Mode Control and nonlinear Adaptive Backstepping control of a Permanent Magnet Synchronous Machine Drive" WSEAS TRANSACTIONS on SYSTEMS and CONTROL, pp86-100, Vol.9 No.1, February 2014.

[31] B.BOSSOUFI, M.KARIM, S.IONITA, A.LAGRIOUI, "Nonlinear Non Adaptive Backstepping with Sliding-Mode Torque Control Approach for PMSM Motor" Journal of Electrical Systems JES, pp236-248. Vol.8 No.2, June 2012.

[32] B.BOSSOUFI, M.KARIM, S.IONITA, A.LAGRIOUI, "Low-Speed Sensorless Control of PMSM Motor drive Using a NONLINEAR Approach BACKSTEPPING Control: FPGA-Based Implementation" Journal of Theoretical and Applied Information Technology JATIT, pp154-166, Vol. 36 No.1, 29th February 2012. 